$\begin{array}{ll}\text { Research Square } & \text { Preprints are preliminary reports that have not undergone peer review. } \\ \text { They should not be considered conclusive, used to inform clinical practice, } \\ \text { or referenced by the media as validated information. }\end{array}$

\title{
Association Between Sleep Pattern and Depression in South Korean Adults: Sleep Duration and Sleep Inconsistency Between Weekdays and Weekends
}

\author{
Nam-Hwa Kim \\ Yonsei University College of Medicine \\ Bo-Hyun Lee \\ Yonsei University College of Medicine \\ Young-Woo Cho \\ Yonsei University College of Medicine \\ Yoon Sik Park ( $\sim$ skyparkys2@yuhs.ac) \\ Yonsei University College of Medicine \\ Eun-Cheol Park \\ Yonsei University College of Medicine
}

Research Article

Keywords: sleep duration, sleep duration ratio, depression, mental health, South Korean adults, KNHANES

Posted Date: July 20th, 2021

DOI: https://doi.org/10.21203/rs.3.rs-676940/v1

License: (c) (i) This work is licensed under a Creative Commons Attribution 4.0 International License. Read Full License 


\section{Abstract}

\section{Objectives}

This study aimed to understand the relationship between sleep duration, inconsistency between weekdays and weekends and depression.

\section{Methods}

A total of 10,205 participants were included in the 2016 and 2018 Korea National Health and Nutrition Examination Survey. Sleep duration over a week was calculated by averaging sleep durations on weekdays and weekends. Sleep duration ratio was defined as sleep duration on weekends divided by that on weekdays and depression as Patient Health Questionnaire scores higher than 5 . We stratified the participants by sex and analyzed using multiple logistic regression.

\section{Results}

In men, those who slept more than 9 hours was compared to those who slept between 7 and 7.9 hours. In women, those who slept less than 5.9 hours related to be more depressed. In men who slept for more than 9 hours and over 1.01 times more on weekends than on weekdays showed the highest chance of depression. In women, the highest odds ratio was associated with those who slept less than 5.9 hours and slept more on weekdays than on weekends.

\section{Conclusions}

In men, sleep durations that were too short or long were associated with depression. In women, extremely short sleep durations were associated with depression.

\section{Introduction}

Depression is one of the most common mental health disorders, with more than 264 million individuals suffering from depression worldwide [1]. According to the World Health Organization, depression is the leading cause of disability and suicide [2]. Several studies have reported an association between depression and suicide. Approximately half of those who commit suicide have depression, and up to $15 \%$ of individuals with depression are likely to die from it [3]. In addition, depression is known to have negative impacts on role functioning, quality of life, and physical health [4].

South Korea is no exception. Due to unprecedented economic growth and changes in social values over the last 50 years, the mental state of many South Koreans has not been healthy [5]. The prevalence of depression in South Korea has gradually increased from $4.0 \%$ in 2001 to $5.6 \%$ in 2006 and $6.7 \%$ in 2011 according to a quinquennial epidemiological study [6, 7]. In terms of suicide mortality rate, South Korea ranked in second place among Organization for Economic Co-operation and Development (OECD) countries in 2016 [8].

Depression is a complex mental disorder that is influenced by genetic factors, lifestyle factors, and the interactions between them [9-11]. Of these, sleep is one of the most important lifestyle factors that affect depression [12]. Consequently, several studies have aimed to understand the role of sleep in the incidence of depression. For example, chronic insomnia has been shown to increase the risk of major depressive disorder (MDD), and residual sleep disorders to predict depression relapse [13]. However, the results of previous studies remain controversial. While one cohort study concluded that the relationship between short sleep duration and depression is statistically significant [14], another prospective study concluded that it is not [15]. Therefore, the primary objective of this study was to clarify the relationship between sleep duration and depression, which has been established in previous studies, in Korean adults.

\section{Methods}

\section{Study sample}

The study used the 2016 and 2018 Korean National Health and Nutrition Examination Survey (KNHANES) data. The 2017 survey data that did not include the Patient Health Questionnaire (PHQ-9) were excluded. The KNHANES is a cross-sectional survey that consists of health interviews, health examinations, and nutritional surveys performed annually since 2007 by medical staff and dieticians of the Korean Centers for Disease Control and Prevention to measure the health status, health behaviors, and nutritional intake of people living in South Korea. The KNHANES also aims to provide valid statistics for establishing health policies and evaluating their effects. The KNHANES uses a complex, multistage, and stratified sampling strategy to reliably represent the noninstitutionalized civilian population aged 1 year or more. Among the 16,142 individuals who took part in the 2016 and 2018 KNHANES, participants whose answers were incomplete, whose data were missing, or who were aged less than 19 years were excluded. In total, 10,205 eligible participants were included for statistical analysis.

\section{Variables}

\section{Sleep duration}

The variable of interest was sleep duration. The KNHANES provides information on average sleep duration, calculated over one week, based on surveyed bedtime and wake-up time. The average sleep duration during a week was calculated by averaging sleep durations on weekdays and weekends with different weighting (5/7 for average sleep duration on weekdays and 2/7 for average sleep duration on a weekend). After calculating weekly average sleep duration, we created five categories one hour apart (less than 5.9 hours, 6 to 6.9 hours, 7 to 7.9 hours, 8 to 8.9 hours and more than 9 hours). 
The sleep duration ratio was calculated by dividing the average sleep duration on a weekend with the average sleep duration on weekdays. This indicates a balance of sleep duration between weekends and weekdays. Therefore, a ratio of 1.00 means that sleep duration during the week and weekend were the same. If it was greater than 1.00 then the participant slept more on weekend. On the other hand, if it was below the 1.00 then they slept more on weekday.

\section{Depression: Patient Health Questionnaire - 9 (PHQ-9)}

The feeling of depression was our primary outcome. Depression was broadly defined as a PHQ-9 score higher than 5. The PHQ-9, which consists of nine items corresponding to the actual criteria of DSM-4 for depression diagnosis, is a self-administered diagnostic tool for screening depression and other mental disorders in primary care and other medical settings [16-20]. Each item of the PHQ-9 allows individuals to grade how often they felt disrupted during the past two weeks from 0 (not at all) to 3 (nearly every day). The PHQ-9 is more valid, sensitive, and specific than the PRIME-MD, which is a traditional clinicianadministered tool; PHQ-9 is now commonly used in both clinical and research settings [21]. While a PHQ-9 score lower than 4 indicates that no depressive symptoms were observed and, thus, treatment is not indicated, potential depression patients with mild depressive symptoms, characterized by a PHQ-9 score higher than 5, may benefit from completing the PHQ-9 again. The other covariates in this study were socioeconomic factors, such as sex, age, region, education level, job, household income, marital status, and health-related factors, such as smoking, drinking, body mass index (BMI), physical activity, and stress.

\section{Statistical analyses}

The rate of depression is consistently higher in females than in males [22, 23]. Women are at a greater risk of being diagnosed with depression in their lifetime than are men [23]. Therefore, we stratified participants by sex because it was most likely a confounding variable. Multiple logistic regression modeling was performed with SAS software (version 9.4) to determine the association between sleep duration or sleep duration ratio (variable of interest) and depressive state (the dependent variable) while controlling for other covariates.

\section{Results}

Table 1 shows the general characteristics of the study participants. The total number of participants in this study was 10,205 . There were 4,737 men and 5,468 women. There were 1,243 (12.2\%) participants who on an average slept for less than 5.9 hours per day, 2,511 (24.6\%) who slept between 6 and 6.9 hours, 3,454 (33.8\%) who slept between 7 and 7.9 hours, 2,110 (20.7\%) who slept between 8 and 8.9 hours, and 887 ( $8.7 \%)$ who slept more than 9 hours per day. Regarding the sleep duration ratio, 945 (9.3\%) participants had values less than $0.99,4,873(47.8 \%)$ at 1.0 , and $4,387(43.0 \%)$ more than 1.01 . There were $657(13.9 \%)$ men and 1,270 (23.2\%) women with depression. 
Table 1

General characteristics of the study participants

\begin{tabular}{|c|c|c|c|c|c|c|c|c|c|c|c|c|}
\hline \multirow[t]{4}{*}{ Variables } & \multicolumn{11}{|c|}{ Depression (PHQ-9 > = 5) } & \\
\hline & \multirow{2}{*}{\multicolumn{2}{|c|}{ TOTAL }} & \multicolumn{5}{|c|}{ Male $(n=4737)$} & \multicolumn{5}{|c|}{ Female $(n=5468)$} \\
\hline & & & YES & & NO & & & YES & & NO & & \\
\hline & $\mathbf{N}$ & $\%$ & $\mathbf{N}$ & $\%$ & $\mathbf{N}$ & $\%$ & $\mathbf{P}$ & $\mathbf{N}$ & $\%$ & $\mathbf{N}$ & $\%$ & \\
\hline Total & 10,205 & 100.0 & 657 & 13.9 & 4,080 & 86.1 & & 1,270 & 23.2 & 4,198 & 76.8 & \\
\hline Sleep Duration (Hours) & & & & & & & $<.0001$ & & & & & $<.0001$ \\
\hline$\sim 5.9$ & 1,243 & 12.2 & 109 & 19.5 & 449 & 80.5 & & 232 & 33.9 & 453 & 66.1 & \\
\hline $6 \sim 6.9$ & 2,511 & 24.6 & 159 & 13.2 & 1,043 & 86.8 & & 269 & 20.6 & 1,040 & 79.4 & \\
\hline $7 \sim 7.9$ & 3,454 & 33.8 & 194 & 11.8 & 1,455 & 88.2 & & 398 & 22.0 & 1,407 & 78.0 & \\
\hline $8 \sim 8.9$ & 2,110 & 20.7 & 113 & 12.2 & 813 & 87.8 & & 241 & 20.4 & 943 & 79.6 & \\
\hline $9 \sim$ & 887 & 8.7 & 82 & 20.4 & 320 & 79.6 & & 130 & 26.8 & 355 & 73.2 & \\
\hline Sleep Duration ratio (weekend/weekday) & & & & & & & 0.0506 & & & & & $<.0001$ \\
\hline$\sim 0.99$ & 945 & 9.3 & 66 & 15.9 & 348 & 84.1 & & 129 & 24.3 & 402 & 75.7 & \\
\hline 1 & 4,873 & 47.8 & 332 & 13.7 & 2,089 & 86.3 & & 619 & 25.2 & 1,833 & 74.8 & \\
\hline $1.01 \sim$ & 4,387 & 43.0 & 259 & 15.8 & 1,643 & 84.2 & & 522 & 21.0 & 1963 & 79.0 & \\
\hline Age & & & & & & & 0.1851 & & & & & $<.0001$ \\
\hline $20 \sim 29$ & 1,243 & 12.2 & 86 & 15.4 & 471 & 84.6 & & 235 & 34.3 & 451 & 65.7 & \\
\hline $30 \sim 39$ & 1,859 & 18.2 & 128 & 15.6 & 694 & 84.4 & & 250 & 24.1 & 787 & 75.9 & \\
\hline $40 \sim 49$ & 2,050 & 20.1 & 124 & 13.8 & 772 & 86.2 & & 214 & 18.5 & 940 & 81.5 & \\
\hline $50 \sim 59$ & 1,957 & 19.2 & 109 & 12.7 & 747 & 87.3 & & 219 & 19.9 & 882 & 80.1 & \\
\hline $60 \sim 69$ & 1,701 & 16.7 & 100 & 11.8 & 750 & 88.2 & & 187 & 22.0 & 664 & 78.0 & \\
\hline $70 \sim$ & 1,395 & 13.7 & 110 & 14.6 & 646 & 85.4 & & 165 & 25.8 & 474 & 74.2 & \\
\hline Region & & & & & & & 0.0654 & & & & & 0.525 \\
\hline Metropolitans & 4,862 & 47.6 & 332 & 14.8 & 1,904 & 85.2 & & 600 & 22.8 & 2,026 & 77.2 & \\
\hline Rurals & 5,343 & 52.4 & 325 & 13.0 & 2,176 & 87.0 & & 670 & 23.6 & 2,172 & 76.4 & \\
\hline Educational level & & & & & & & 0.0052 & & & & & 0.002 \\
\hline Under highschool & 6,143 & 60.2 & 413 & 15.1 & 2,328 & 84.9 & & 837 & 24.6 & 2,565 & 75.4 & \\
\hline College & 4,062 & 39.8 & 244 & 12.2 & 1,752 & 87.8 & & 433 & 21.0 & 1,633 & 79.0 & \\
\hline Job & & & & & & & $<.0001$ & & & & & $<.0001$ \\
\hline White & 2,721 & 26.7 & 164 & 11.5 & 1,260 & 88.5 & & 254 & 19.6 & 1,043 & 80.4 & \\
\hline Pink & 1,460 & 14.3 & 93 & 17.7 & 433 & 82.3 & & 200 & 21.4 & 734 & 78.6 & \\
\hline Blue & 2,347 & 23.0 & 191 & 12.2 & 1,377 & 87.8 & & 153 & 19.6 & 626 & 80.4 & \\
\hline None & 3,677 & 36.0 & 209 & 17.1 & 1,010 & 82.9 & & 663 & 27.0 & 1,795 & 73.0 & \\
\hline Household income & & & & & & & $<.0001$ & & & & & $<.0001$ \\
\hline High & 3,123 & 30.6 & 156 & 10.6 & 1,309 & 89.4 & & 285 & 17.2 & 1,373 & 82.8 & \\
\hline Middle high & 2,895 & 28.4 & 158 & 11.6 & 1,200 & 88.4 & & 348 & 22.6 & 1,189 & 77.4 & \\
\hline Middle low & 2,491 & 24.4 & 181 & 15.8 & 964 & 84.2 & & 329 & 24.4 & 1,017 & 75.6 & \\
\hline Low & 1,696 & 16.6 & 162 & 21.1 & 607 & 78.9 & & 308 & 33.2 & 619 & 66.8 & \\
\hline Marriage & & & & & & & $<.0001$ & & & & & $<.0001$ \\
\hline Yes & 7,257 & 71.1 & 407 & 11.6 & 3,087 & 88.4 & & 731 & 19.4 & 3,032 & 80.6 & \\
\hline No & 2,948 & 28.9 & 250 & 20.1 & 993 & 79.9 & & 539 & 31.6 & 1,166 & 68.4 & \\
\hline
\end{tabular}




\begin{tabular}{|c|c|c|c|c|c|c|c|c|c|c|c|c|}
\hline \multirow[t]{4}{*}{ Variables } & \multicolumn{11}{|c|}{ Depression (PHQ-9 > = 5) } & \\
\hline & \multirow{2}{*}{\multicolumn{2}{|c|}{ TOTAL }} & \multicolumn{5}{|c|}{ Male $(n=4737)$} & \multicolumn{5}{|c|}{ Female $(n=5468)$} \\
\hline & & & \multicolumn{2}{|l|}{ YES } & \multicolumn{2}{|l|}{ NO } & & \multicolumn{2}{|l|}{ YES } & \multicolumn{3}{|l|}{ NO } \\
\hline & $\mathbf{N}$ & $\%$ & $\mathbf{N}$ & $\%$ & $\mathbf{N}$ & $\%$ & $\mathbf{P}$ & $\mathbf{N}$ & $\%$ & $\mathbf{N}$ & $\%$ & \\
\hline Smoke & & & & & & & 0.0442 & & & & & $<.0001$ \\
\hline Yes & 4,431 & 43.4 & 536 & 14.4 & 3,187 & 85.6 & & 299 & 42.2 & 409 & 57.8 & \\
\hline No & 5,774 & 56.6 & 121 & 11.9 & 893 & 88.1 & & 971 & 20.4 & 3,789 & 79.6 & \\
\hline Drink & & & & & & & 0.4018 & & & & & 0.0001 \\
\hline $2 \sim 4$ times / week & 2,552 & 25.0 & 249 & 14.1 & 1,519 & 85.9 & & 228 & 29.1 & 556 & 70.9 & \\
\hline $2 \sim 4$ times / month & 2,557 & 25.1 & 166 & 12.8 & 1,131 & 87.2 & & 291 & 23.1 & 969 & 76.9 & \\
\hline Never or occasionally & 5,096 & 49.9 & 242 & 14.5 & 1,430 & 85.5 & & 751 & 21.9 & 2,673 & 78.1 & \\
\hline BMIt & & & & & & & 0.6075 & & & & & 0.2846 \\
\hline Obese $(\geq 25)$ & 3,532 & 34.6 & 278 & 14.2 & 1,683 & 85.8 & & 380 & 24.2 & 1,191 & 75.8 & \\
\hline Normal or under-weight(<25) & 6,673 & 65.4 & 379 & 13.7 & 2,397 & 86.3 & & 890 & 22.8 & 3,007 & 77.2 & \\
\hline Physical activity & & & & & & & 0.1757 & & & & & 0.8939 \\
\hline Yes & 3,922 & 38.4 & 291 & 13.1 & 1,923 & 86.9 & & 534 & 31.3 & 1,174 & 68.7 & \\
\hline No & 5,683 & 55.7 & 366 & 14.5 & 2,157 & 85.5 & & 736 & 23.3 & 2,424 & 76.7 & \\
\hline Stress & & & & & & & $<.0001$ & & & & & $<.0001$ \\
\hline Lot & 2,740 & 26.8 & 374 & 32.9 & 762 & 67.1 & & 782 & 48.8 & 822 & 51.2 & \\
\hline Little & 7,465 & 73.2 & 283 & 7.9 & 3,318 & 92.1 & & 488 & 12.6 & 3,376 & 87.4 & \\
\hline \multicolumn{13}{|l|}{ BMI body mass index } \\
\hline tObesity status defined by BN & 14 Clin & Prac & delin & for 0 & erweigh & and $\mathrm{Ob}$ & sity in & & & & & \\
\hline
\end{tabular}

Table 2 shows the odd ratio results of multiple logistic regression model between depression and sleep duration or sleep duration ratio when other covariates were controlled. For men, the odds ratio among those with sleep duration less than 5.9 hours per day (Odds Ratio [OR] $=1.32,95 \%$ confidence interval $[\mathrm{Cl}]=$ 0.94-1.87) was much higher, and the odds ratio among those with sleep duration between 6 and 6.9 hours per day $(\mathrm{OR}=1.04,95 \% \mathrm{Cl}=0.77-1.40)$ was slightly higher than that of men who slept between 7 and 7.9 hours per day (reference group). Additionally, the odds ratio for men with sleep duration of more than 9 hours per day $(\mathrm{OR}=1.51,95 \% \mathrm{Cl}=1.01-2.26)$ was much higher and the odds ratio for those with sleep duration between 6 and 6.9 hours per day $(\mathrm{OR}=$ $1.02,95 \% \mathrm{Cl}=0.74-1.40$ ) was slightly higher than that of those with sleep duration between 7 and 7.9 hours per day. Thus, the odds ratios were associated with sleep duration in a U-shaped, that is, both shorter and longer sleep durations resulted in higher odds ratios in men. In women, the odds ratios among those with sleep duration less than 5.9 hours per day $(\mathrm{OR}=1.60,95 \% \mathrm{Cl}=1.23-2.08)$ and more than 9 hours per day $(\mathrm{OR}=1.26,95 \% \mathrm{Cl}=0.94-1.70)$ were higher than that among those with sleep duration between 7 and 7.9 hours per day. The odds ratio among men with high stress $(\mathrm{OR}=6.67,95 \% \mathrm{Cl}=5.38-$ 8.26) was significantly higher than that among men with low stress (reference group). The odds ratio of women with high stress $(\mathrm{OR}=5.84,95 \% \mathrm{Cl}=5.01-$ 6.82) was also significantly higher than that of women with low stress. Similar results in men and women increase the credibility of this finding. Other covariates such as age, job, household income, marriage, and smoking also showed statistical significance. 
Table 2

Multiple logistic regression analysis of depression

\begin{tabular}{|c|c|c|c|c|c|c|c|c|c|c|c|}
\hline \multirow[t]{3}{*}{ Variables } & \multicolumn{11}{|c|}{ Depression (PHQ-9 > = 5) } \\
\hline & \multicolumn{5}{|l|}{ Male } & \multicolumn{6}{|c|}{ Female } \\
\hline & OR & \multicolumn{4}{|c|}{$95 \% \mathrm{Cl}$} & OR & & \multicolumn{4}{|c|}{$95 \% \mathrm{Cl}$} \\
\hline \multicolumn{12}{|c|}{ Sleep Duration (Hours) } \\
\hline$\sim 5.9$ & 1.32 & $(0.94$ & - & 1.87 & ) & 1.60 & ( & 1.23 & - & 2.08 & ) \\
\hline $6 \sim 6.9$ & 1.04 & ( $\quad 0.77$ & - & 1.40 & ) & 0.98 & ( & 0.79 & - & 1.22 & ) \\
\hline $7 \sim 7.9$ & 1.00 & & & & & 1.00 & & & & & \\
\hline $8 \sim 8.9$ & 1.02 & $(\quad 0.74$ & - & 1.40 & ) & 0.96 & ( & 0.77 & - & 1.19 & ) \\
\hline $9 \sim$ & 1.51 & ( 1.01 & - & 2.26 & ) & 1.26 & ( & 0.94 & - & 1.70 & ) \\
\hline \multicolumn{12}{|c|}{ Sleep Duration ratio (weekend/weekday) } \\
\hline$\sim 0.99$ & 1.29 & $(0.88$ & - & 1.89 & ) & 0.96 & ( & 0.71 & - & 1.30 & ) \\
\hline 1 & 1.00 & & & & & 1.00 & & & & & \\
\hline $1.01 \sim$ & 0.98 & $(0.88$ & - & 1.13 & ) & 0.88 & ( & 0.68 & - & 0.99 & ) \\
\hline \multicolumn{12}{|l|}{ Age } \\
\hline $20 \sim 29$ & 1.00 & & & & & 1.00 & & & & & \\
\hline $30 \sim 39$ & 1.73 & $(1.15$ & - & 2.62 & ) & 0.82 & ( & 0.60 & - & 1.12 & ) \\
\hline $40 \sim 49$ & 1.98 & $(1.26$ & - & 3.10 & ) & 0.73 & ( & 0.53 & - & 0.99 & ) \\
\hline $50 \sim 59$ & 1.72 & ( 1.09 & - & 2.71 & ) & 0.93 & ( & 0.68 & - & 1.28 & ) \\
\hline $60 \sim 69$ & 1.53 & ( 0.96 & - & 2.44 & ) & 0.84 & ( & 0.58 & - & 1.21 & ) \\
\hline $70 \sim$ & 1.58 & ( 0.95 & - & 2.63 & ) & 0.68 & ( & 0.46 & - & 1.03 & ) \\
\hline \multicolumn{12}{|l|}{ Region } \\
\hline Metropolitans & 1.00 & & & & & 1.00 & & & & & \\
\hline Rurals & 0.86 & ( $\quad 0.69$ & - & 1.06 & ) & 1.01 & ( & 0.84 & - & 1.21 & ) \\
\hline \multicolumn{12}{|l|}{ Educational level } \\
\hline Under highschool & 1.00 & & & & & 1.00 & & & & & \\
\hline College & 1.04 & ( 0.81 & - & 1.34 & ) & 0.95 & ( & 0.77 & - & 1.18 & ) \\
\hline \multicolumn{12}{|l|}{ Job } \\
\hline White & 1.00 & & & & & 1.00 & & & & & \\
\hline Pink & 1.62 & ( 1.16 & - & 2.28 & ) & 0.98 & ( & 0.73 & - & 1.32 & ) \\
\hline Blue & 1.16 & ( 0.84 & - & 1.62 & ) & 1.04 & ( & 0.76 & - & 1.42 & ) \\
\hline None & 1.51 & ( 1.06 & - & 2.15 & ) & 1.63 & ( & 1.29 & - & 2.06 & ) \\
\hline \multicolumn{12}{|l|}{ Household income } \\
\hline High & 1.00 & & & & & 1.00 & & & & & \\
\hline Middle high & 0.99 & ( 0.73 & - & 1.35 & ) & 1.29 & ( & 1.02 & - & 1.61 & ) \\
\hline Middle low & 1.45 & ( 1.07 & - & 1.97 & ) & 1.33 & ( & 1.06 & - & 1.67 & ) \\
\hline Low & 2.01 & ( 1.37 & - & 2.94 & ) & 1.89 & ( & 1.40 & - & 2.57 & ) \\
\hline \multicolumn{12}{|l|}{ Marriage } \\
\hline Yes & 1.00 & & & & & 1.00 & & & & & \\
\hline No & 2.16 & ( 1.68 & - & 2.78 & ) & 1.63 & ( & 1.34 & - & 1.98 & ) \\
\hline \multicolumn{12}{|l|}{ Smoke } \\
\hline Yes & 1.22 & ( 0.89 & - & 1.68 & ) & 2.03 & ( & 1.62 & - & 2.54 & ) \\
\hline
\end{tabular}




\begin{tabular}{|c|c|c|c|c|c|c|c|c|c|c|c|c|}
\hline \multirow[t]{3}{*}{ Variables } & \multicolumn{12}{|c|}{ Depression (PHQ-9 > = 5) } \\
\hline & \multicolumn{6}{|c|}{ Male } & \multicolumn{6}{|c|}{ Female } \\
\hline & OR & & \multicolumn{4}{|c|}{$95 \% \mathrm{Cl}$} & OR & & \multicolumn{4}{|c|}{$95 \% \mathrm{Cl}$} \\
\hline No & 1.00 & & & & & & 1.00 & & & & & \\
\hline \multicolumn{13}{|l|}{ Drink } \\
\hline $2 \sim 4$ times / week & 0.90 & ( & 0.69 & - & 1.17 & ) & 1.23 & ( & 0.97 & - & 1.56 & ) \\
\hline $2 \sim 4$ times / month & 0.92 & ( & 0.70 & - & 1.21 & ) & 1.10 & ( & 0.88 & - & 1.36 & ) \\
\hline Never or occasionally & 1.00 & & & & & & 1.00 & & & & & \\
\hline \multicolumn{13}{|l|}{ BMlt } \\
\hline Obese $(\geq 25)$ & 1.07 & ( & 0.86 & - & 1.34 & ) & 0.97 & ( & 0.80 & - & 1.16 & ) \\
\hline Normal or under-weight(<25) & 1.00 & & & & & & 1.00 & & & & & \\
\hline \multicolumn{13}{|l|}{ Physical activity } \\
\hline Yes & 1.00 & & & & & & 1.00 & & & & & \\
\hline No & 1.03 & ( & 0.85 & - & 1.25 & ) & 0.94 & ( & 0.78 & - & 1.13 & ) \\
\hline \multicolumn{13}{|l|}{ Stress } \\
\hline Lot & 6.67 & ( & 5.38 & - & 8.26 & ) & 5.84 & ( & 5.01 & - & 6.82 & ) \\
\hline Little & 1.00 & & & & & & 1.00 & & & & & \\
\hline
\end{tabular}

Table 3 shows the results of the subgroup analysis by covariates for the sleep duration ratio in men and women. In men who slept more than 9 hours per day on average, the odds ratio was slightly higher in the group with a sleep duration ratio of $1.00(\mathrm{OR}=1.45,95 \% \mathrm{Cl}=0.82-2.57)$ and much higher in the group with a sleep duration ratio of over $1.01(\mathrm{OR}=2.33,95 \% \mathrm{Cl}=1.08-5.03)$ than in the group with a sleep duration ratio less than $0.99(\mathrm{OR}=1.37,95 \% \mathrm{Cl}=0.47-$ 4.04). Among women who slept more than 9 hours per day on average, the odds ratio was slightly higher in the group with a sleep duration ratio of 1.00 (OR $=$ $1.74,95 \% \mathrm{Cl}=1.21-2.51)$ and much higher in the group with a sleep duration ratio less than $0.99(\mathrm{OR}=4.94,95 \% \mathrm{Cl}=1.98-12.37)$ than in the group with a sleep duration ratio over $1.01(\mathrm{OR}=0.87,95 \% \mathrm{Cl}=0.34-2.21)$. 
Table 3

Subgroup analysis of depression

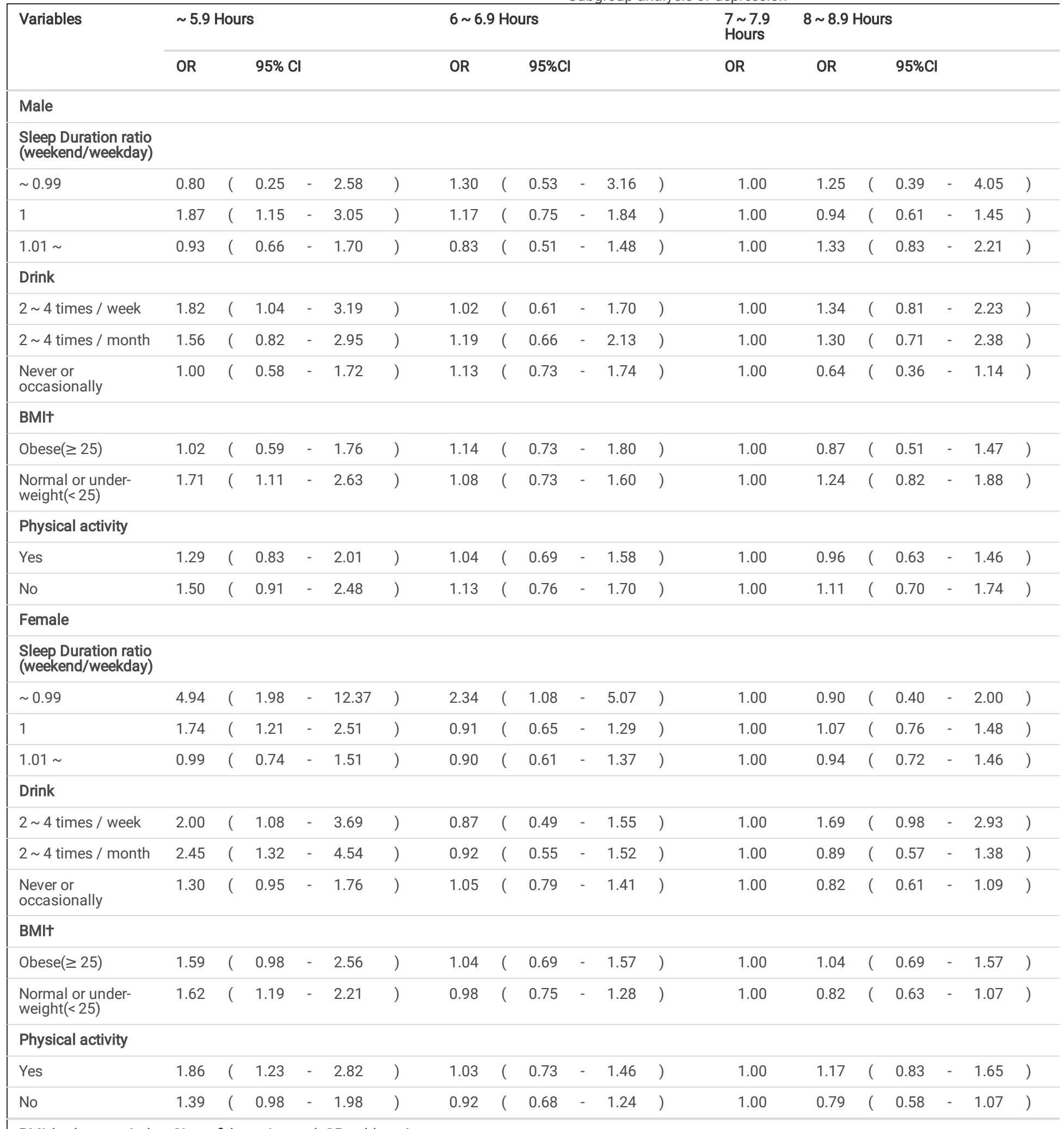

$\mathrm{BMI}$, body mass index, $\mathrm{Cl}$, confidence interval, OR, odds ratio

Among men who slept less than 5.9 hours per day on average, the odds ratio was the highest in the group that consumed alcohol between 2 and 4 times per week $(\mathrm{OR}=1.82,95 \% \mathrm{Cl}=1.04-3.19)$, followed by the group that drank between 2 and 4 times per month $(\mathrm{OR}=1.56,95 \% \mathrm{Cl}=0.82-2.95)$, and the lowest in the group that drank between 2 and 4 times per week $(\mathrm{OR}=1.00,95 \% \mathrm{Cl}=0.58-1.72)$, compared to those who slept between 7 and 7.9 hours per day (reference group). Moreover, for men who slept for more than 9 hours per day, the odds ratio was higher in the group with no physical activity $(\mathrm{OR}=1.65,95 \%$ $\mathrm{Cl}=0.97-2.79)$ than in the physically active group $(\mathrm{OR}=1.44,95 \% \mathrm{Cl}=0.78-2.68)$, and it was higher in the obese group $(\mathrm{OR}=1.82,95 \% \mathrm{Cl}=1.03-3.23)$ than in the group that had a normal weight or was underweight $(\mathrm{OR}=1.41,95 \% \mathrm{Cl}=0.78-2.54)$, compared to those who slept between 7 and 7.9 hours per day on average. 


\section{Discussion}

The purpose of this study was to investigate the association between sleep duration and depressive status in Korean adults. The results indicate that the odds ratios of depression among Korean adults varied depending on their sleep duration. Sleep duration of less than 5.9 hours per day and sleep duration longer than 9 hours per day were highly associated with a depressive state. The relationship between sleep duration and the rate of depression was more apparent in men than in women. This result concurred with previous findings that indicated that both short and long sleep durations increased the risk of depression among adults who participated in seven prospective studies [24]. Short sleep durations seem to negatively affect one's depressive state by increasing daytime tiredness [27], which predicts the risk of depression [25]. Daytime tiredness, which includes sleepiness and fatigue, increases negative events and negative emotional states that predispose individuals to depression [26]

Findings from the subgroup analysis on the sleep duration ratio of those who slept more on weekends than on weekdays showed a higher odds ratio of depression in men who slept more than 9 hours per day on average. This indicates that both excessive sleeping time and irregular weekend-centered sleeping patterns increase the risk of depression. Although the variation of sleep duration on weekdays and weekends was associated with depressive symptoms in South Korean workers, the direction of this association has not been clarified before [27]. In contrast, we found that sleeping more on weekends was associated with a lower risk of depression in women who slept less than 5.9 hours per day on average. This indicates that catching up on sleep during a weekend and having enough sleeping on a weekend can effectively relieve the weekday sleep debt and the feelings of tiredness that accumulate during weekdays [28].

In the subgroup analysis for other covariates, the risk of depression in men was higher for those who slept less than 5.9 hours per day and those who drank frequently. These results demonstrate that depression can lead to unhealthy, excessive alcohol consumption, which causes many other negative physical and psychological effects [29]. Long sleep durations seem to result in a poor outcomes in terms of depression because a long sleep duration is correlated with low physical activity $[30,31]$. The same conclusion can also be drawn from the results of the subgroup analysis for other covariates, which demonstrated that both physically non-active or obese men and women, who slept for more than 9 hours per day, were more susceptible to depression than were those who are physically active or of normal weight. Physical activity increases the level of dopamine and serotonin neurotransmitters [32], increases the secretion of endorphin [33], distracts from stressful stimuli [34], and improves self-efficacy and self-esteem [35], thus positively affecting the depressive state. This mechanism may explain the results of this study.

This study had a few limitations. First, the design of the study was cross-sectional and not longitudinal. Thus, the study was not able to establish a causal relationship between sleep duration and depression. Second, the measurement of sleep duration relied on a self-reported survey method, which is considered less valid than actigraphy and golden-standard polysomnography [36]. Third, sleep quality was not considered when investigating the relationship between sleep duration and depressive state, as the KNHANES data did not include any indicators of sleep quality. Finally, the study does not explain the underlying biological and biochemical mechanisms by which sleep duration affects depression and vice versa. Therefore, additional studies that measure sleep duration and sleep quality using more objective methods are required. Although sleep is potentially associated with neurotransmitter imbalance, HPA disturbance, increased oxidative and nitrosative stresses, neuroprogression, and dysregulated immuno-inflammation, which are five pathogenic pathways that cause MDD, further studies about the exact mechanisms are also needed [12].

This study is important because it focused not only on sleep duration but also on the sleep duration ratio between weekends and weekdays as factors related to depression. It also included a large sample population and conducted stratified analyses by sex, which further increased the study validity.

The findings of this study have elucidated the importance of lifestyle factors, especially sleep duration, in depression. Comparing with that in other OECD countries, there is a current lack of mental and psychological health policies for patients with depression and those who are potentially depressed in South Korea [37]. To make matters worse, few studies have focused on sleep-related factors. This study confirms the necessity of establishing new policies and reinforcing current policies that target depression in South Korea.

\section{Conclusion}

Sleep duration and sleep duration ratio were found to be associated with depression. Sleep durations that are too long or too short may lead to a depressive state. Such observations were more apparent in men than in women. While excessive sleep contributed to the lack of exercise in daily life, sleep deficiency leads to a feeling of tiredness. Different sleep duration conditions brought about different impacts on the sleep duration ratio and its effect on depression. Sleeping longer on the weekend versus weekdays functioned differently among those with long and short sleep durations as irregular sleep patterns and as an effective tiredness reliever, respectively. These associations have not yet been confirmed by longitudinal or casual studies. The results of this study may be used as a reference when investigating sleep-related variables to reduce and prevent depression in the South Korean society using appropriate governmentdriven mental healthcare policies.

\section{Declarations}

\section{Conflict of Interest}

The authors declare no conflicts of interest associated with the materials presented in this paper.

\section{Acknowledgments}

This study used data from the seventh Korea National Health and Nutrition Examination Survey (KNHANES \-1\&3), 2016 \& 2018, Korea Centers for Disease Control and Prevention. 


\section{Author Contributions}

Conceptualization: NHK and BYL Data curation: YSP, NHK, BYL, and YWC Formal analysis: YSP, NHK, BYL, and YWC Methodology: YSP, NHK, BYL, and YWC. Project administration: NHK. Writing original draft: NHK Writing - review and editing: YSP and ECP.

\section{References}

1. James, S. L. et al. Global, regional, and national incidence, prevalence, and years lived with disability for 354 diseases and injuries for 195 countries and territories, 1990-2017: a systematic analysis for the Global Burden of Disease Study 2017. The Lancet, 392, 1789-1858 https://doi.org/10.1016/S01406736(18)32279-7 (2018).

2. WHO. (World Health Organization, Geneva, 2018).

3. Simon, G. E. \& VonKorff, M. Suicide mortality among patients treated for depression in an insured population. Am J Epidemiol, 147, 155-160 https://doi.org/10.1093/oxfordjournals.aje.a009428 (1998).

4. Gallegos-Carrillo, K. et al. Role of depressive symptoms and comorbid chronic disease on health-related quality of life among community-dwelling older adults. Journal of Psychosomatic Research, 66, 127-135 https://doi.org/10.1016/j.jpsychores.2008.07.007 (2009).

5. Koo, S. K. Depression Status in Korea. Osong Public Health Res Perspect, 9, 141-142 https://doi.org/10.24171/j.phrp.2018.9.4.01 (2018).

6. Cho, M. J. \& Lee, J. Y. Epidemiology of Depressive Disorders in Korea. Psychiatry Investig, 2, 22-27 (2005).

7. Cho, M. J. et al. Prevalence and Correlates of DSM-IV Mental Disorders in South Korean Adults: The Korean Epidemiologic Catchment Area Study 2011. Psychiatry Investig, 12, 164-170 https://doi.org/10.4306/pi.2015.12.2.164 (2015).

8. OECD statistics. Causes of Mortality: Intentional self-harm. https://stats.oecd.org/

9. Caspi, A. et al. Influence of Life Stress on Depression: Moderation by a Polymorphism in the 5-HTT Gene., 301, 386-389 https://doi.org/10.1126/science.1083968 (2003).

10. Boden, J. M. \& Fergusson, D. M. Alcohol and depression., 106, 906-914 https://doi.org/10.1111/j.1360-0443.2010.03351.x (2011).

11. Haeffel, G. J. et al. Association between polymorphisms in the dopamine transporter gene and depression: evidence for a gene-environment interaction in a sample of juvenile detainees. Psychol Sci, 19, 62-69 https://doi.org/10.1111/j.1467-9280.2008.02047.x (2008).

12. Lopresti, A. L., Hood, S. D. \& Drummond, P. D. A review of lifestyle factors that contribute to important pathways associated with major depression: diet, sleep and exercise. J Affect Disord, 148, 12-27 https://doi.org/10.1016/j.jad.2013.01.014 (2013).

13. Sarris, J., O'Neil, A., Coulson, C. E., Schweitzer, I. \& Berk, M. Lifestyle medicine for depression. BMC Psychiatry, 14, 107 https://doi.org/10.1186/1471-244x14-107 (2014)

14. Gehrman, P. et al. Predeployment Sleep Duration and Insomnia Symptoms as Risk Factors for New-Onset Mental Health Disorders Following Military Deployment., 36, 1009-1018 https://doi.org/10.5665/sleep.2798 (2013).

15. Yokoyama, E. et al. Association between depression and insomnia subtypes: a longitudinal study on the elderly in Japan., 33, 1693-1702 https://doi.org/10.1093/sleep/33.12.1693 (2010).

16. Kroenke, K., Spitzer, R. L. \& Williams, J. B. The PHQ-9: validity of a brief depression severity measure. J Gen Intern Med, 16, 606-613 https://doi.org/10.1046/j.1525-1497.2001.016009606.x (2001).

17. Kroenke, K. \& Spitzer, R. L. The PHQ-9: A new depression diagnostic and severity measure. Psychiatric Annals, 32, 509-515 https://doi.org/10.3928/00485713-20020901-06 (2002).

18. Spitzer, R. L., Kroenke, K. \& Williams, J. B. Validation and utility of a self-report version of PRIME-MD: the PHQ primary care study. Primary Care Evaluation of Mental Disorders. Patient Health Questionnaire. Jama, 282, 1737-1744 https://doi.org/10.1001/jama.282.18.1737 (1999).

19. Wittkampf, K. A., Naeije, L., Schene, A. H., Huyser, J. \& van Weert, H. C. Diagnostic accuracy of the mood module of the Patient Health Questionnaire: a systematic review. Gen Hosp Psychiatry, 29, 388-395 https://doi.org/10.1016/j.genhosppsych.2007.06.004 (2007).

20. Gilbody, S., Richards, D., Brealey, S. \& Hewitt, C. Screening for depression in medical settings with the Patient Health Questionnaire (PHQ): a diagnostic meta-analysis. J Gen Intern Med, 22, 1596-1602 https://doi.org/10.1007/s11606-007-0333-y (2007).

21. Spitzer, R. L., Williams, J. B., Kroenke, K., Hornyak, R. \& McMurray, J. Validity and utility of the PRIME-MD patient health questionnaire in assessment of 3000 obstetric-gynecologic patients: the PRIME-MD Patient Health Questionnaire Obstetrics-Gynecology Study. Am J Obstet Gynecol, 183, 759-769 https://doi.org/10.1067/mob.2000.106580 (2000).

22. Weissman, M. M. et al. Cross-national epidemiology of major depression and bipolar disorder., 276, 293-299 (1996).

23. Kessler, R. C. et al. Lifetime Prevalence and Age-of-Onset Distributions of DSM-IV Disorders in the National Comorbidity Survey Replication. Archives of General Psychiatry, 62, 593-602 https://doi.org/10.1001/archpsyc.62.6.593 (2005).

24. Zhai, L., Zhang, H., Zhang, D. \& SLEEP DURATION AND DEPRESSION AMONG ADULTS: A META-ANALYSIS OF PROSPECTIVE STUDIES. Depress Anxiety, 32, 664-670 https://doi.org/10.1002/da.22386 (2015).

25. Shen, J., Barbera, J. \& Shapiro, C. M. Distinguishing sleepiness and fatigue: focus on definition and measurement. Sleep Med Rev, 10, 63-76 https://doi.org/10.1016/j.smrv.2005.05.004 (2006).

26. Morris, B. H., Bylsma, L. M. \& Rottenberg, J. Does emotion predict the course of major depressive disorder? A review of prospective studies. Br J Clin Psychol, 48, 255-273 https://doi.org/10.1348/014466508x396549 (2009). 
27. Han, K. T. \& Kim, S. J. Instability in daily life and depression: The impact of sleep variance between weekday and weekend in South Korean workers. Health Soc Care Community, 28, 874-882 https://doi.org/10.1111/hsc.12918 (2020).

28. Oh, Y. H., Kim, H., Kong, M., Oh, B. \& Moon, J. H. Association between weekend catch-up sleep and health-related quality of life of Korean adults. Med. (Baltim), 98, e14966 https://doi.org/10.1097/md.0000000000014966 (2019).

29. Gardner, J. D. \& Mouton, A. J. Alcohol effects on cardiac function. Compr Physiol, 5, 791-802 https://doi.org/10.1002/cphy.c140046 (2015).

30. Stranges, S. et al. Correlates of short and long sleep duration: a cross-cultural comparison between the United Kingdom and the United States: the Whitehall II Study and the Western New York Health Study. Am J Epidemiol, 168, 1353-1364 https://doi.org/10.1093/aje/kwn337 (2008).

31. Harvey, S. B., Hotopf, M., Overland, S. \& Mykletun, A. Physical activity and common mental disorders. Br J Psychiatry, 197, $357-364$ https://doi.org/10.1192/bjp.bp.109.075176 (2010).

32. Weicker, H. \& Strüder, H. K. Influence of exercise on serotonergic neuromodulation in the brain., 20, 35-47 https://doi.org/10.1007/s007260170064 (2001).

33. Janal, M. N., Colt, E. W., Clark, W. C. \& Glusman, M. Pain sensitivity, mood and plasma endocrine levels in man following long-distance running: effects of naloxone., 19, 13-25 https://doi.org/10.1016/0304-3959(84)90061-7 (1984).

34. Salmon, P. Effects of physical exercise on anxiety, depression, and sensitivity to stress: a unifying theory. Clin Psychol Rev, 21, 33-61 https://doi.org/10.1016/s0272-7358(99)00032-x (2001).

35. Paluska, S. A. \& Schwenk, T. L. Physical activity and mental health: current concepts. Sports Med, 29, 167-180 https://doi.org/10.2165/00007256200029030-00003 (2000).

36. Marino, M. et al. Measuring sleep: accuracy, sensitivity, and specificity of wrist actigraphy compared to polysomnography., 36, 1747-1755 https://doi.org/10.5665/sleep.3142 (2013).

37. OECD. Caring for Quality in Health. (2017). 